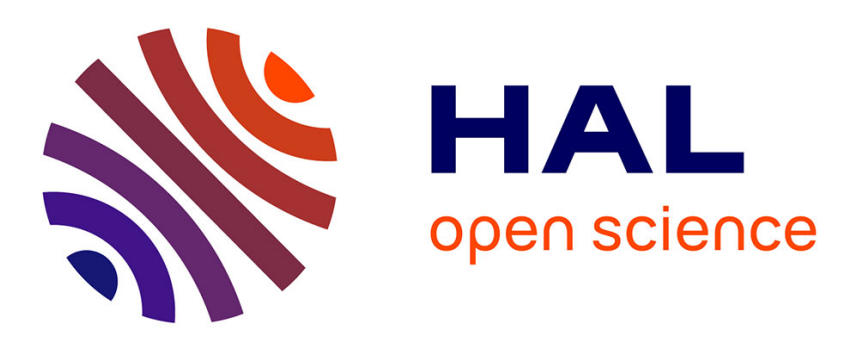

\title{
Standard units for ElectroChromic Shift measurements in plant biology
}

\author{
Charlie Mathiot, Jean Alric
}

\section{To cite this version:}

Charlie Mathiot, Jean Alric. Standard units for ElectroChromic Shift measurements in plant biology. Journal of Experimental Botany, 2021, 72 (18), pp.6467-6473. hal-03368441

\section{HAL Id: hal-03368441 \\ https://hal.science/hal-03368441}

Submitted on 6 Oct 2021

HAL is a multi-disciplinary open access archive for the deposit and dissemination of scientific research documents, whether they are published or not. The documents may come from teaching and research institutions in France or abroad, or from public or private research centers.
L'archive ouverte pluridisciplinaire HAL, est destinée au dépôt et à la diffusion de documents scientifiques de niveau recherche, publiés ou non, émanant des établissements d'enseignement et de recherche français ou étrangers, des laboratoires publics ou privés. 
1 Standard units for ElectroChromic Shift (ECS) measurements in plant biology

2

3 Charlie Mathiot ${ }^{1,2}$, Jean Alric ${ }^{1}$

4

1 Aix Marseille Univ, CEA, CNRS, BIAM, UMR 7265, Photosynthesis and Environment, 6 Saint Paul-Lez-Durance, France F-13108

$7{ }^{2}$ Groupe Biomasse 3G, CEA Tech, CEA Cadarache, 13108 Saint-Paul-Lez-Durance, France. 8

9 Highlight

10 ElectroChromic Shift can be used to measure the light-response curves of electron transport 11 rate, the fraction of open photosystems and a transmission coefficient for the photosynthetic 12 chain.

Abstract

The absorbance shift of pigments is proportional to the membrane potential $(\Delta \psi)$ in plants, green algae, and many photosynthetic bacteria. It is currently denoted as ElectroChromic Shift (ECS) at 515-520 $\mathrm{nm}$ for plant carotenoids. It is increasingly being used for phenotyping plants for traits related to photosynthesis or chloroplast metabolism because it is a noninvasive technique and also because more instruments are now commercially available from various manufacturers. The ECS technique is currently used to monitor the post-illumination decay of the proton-motive force ( $p m f)$, but it has a yet more general use for quantitative studies on photosynthetic energy transduction. Here we briefly summarize the basic knowledge on ECS, emphasize the full potential of this technique, and propose a quantitative analysis of the photosynthetic performance with the definition of a transmission coefficient for electrons along the photosynthetic chain.

\section{Keywords}

29 Photosynthesis, chloroplast, thylakoid, cyclic electron flow, ATP-synthase

\section{Abbreviations}

ECS, ElectroChromic Shift

$34 \Delta \psi$, membrane potential 
$I$, initial electron flow rate

$J$, steady-state electron flow rate

$\mathrm{PS}_{\mathrm{o}}$, open photosystems

\section{Introduction}

ECS signal was first reported as P515 (Duysens, 1954), an absorbance increase $(\Delta \mathrm{A})$ peaking around $515 \mathrm{~nm}$. This signal was attributed to a change in absorption of carotenoids (Witt, 1979), proportional to the membrane potential $(\Delta \psi)$. This signal was then used for the study of proton flow through ATPase (Junge, 1970) and the "slow" electrogenic phase of cyt $b_{6} f$ complex (Joliot and Delosme, 1974). More recently, the ECS decay rate after a continuous illumination was related to photosynthetic electron flow, allowing this technique to measure a flux as for any other reaction intermediate in the photosynthetic chain (Sacksteder and Kramer, 2000). This concept deserves explanation: if the ECS signal is constant over time, as observed at steady-state under continuous illumination, then the reactions building the protonmotive force (light-induced electron and proton transport) are exactly compensated by those consuming the proton-motive force (by ATPase in the dark), so that the post-illumination decay rate of ECS (membrane conductivity $g_{\mathrm{H}}{ }^{+}$, in $\mathrm{s}^{-1}$ ) is exactly equal to the electron transfer rate through the photosystems. This contribution had a very broad impact on the photosynthesis and chloroplast research community, it allowed for semi-quantitative studies of energy-dependent non-photochemical chlorophyll fluorescence quenching (qE) in relation to electron and proton flow (Kanazawa and Kramer, 2002), of cyclic and linear electron flows by comparing WT and pgr5 plants (Avenson et al., 2005), of the parsing of the pmf between $\Delta \psi$ and $\Delta \mathrm{pH}$ (Cruz et al., 2001) and the recent identification of the thylakoid proton antiporter KEA3 (Kunz et al., 2014).

The rate of a reaction (in $\mathrm{s}^{-1}$ ) defines enzyme kinetics. Yet, for the characterization of an integrated pathway like photosynthesis, the flux (in number of particles, per unit time per unit area) is a much more relevant parameter. Kramer and co-workers showed that the amplitude of the ECS decay is proportional to the proton motive force $(p m f)$. Therefore, the efflux of protons through ATPase $\left(v_{\mathrm{H}}^{+}\right)$can be related to its conductivity $g_{\mathrm{H}}^{+}$as follows: $v_{\mathrm{H}}^{+} \sim p m f \times g_{\mathrm{H}}^{+}$(Avenson et al., 2004). The units for this proton efflux are not always specified (often in arbitrary units) but they should be $\mu \mathrm{mol}_{\mathrm{H}}{ }^{+} \mathrm{m}^{-2} \mathrm{~s}^{-1}$, like the electron transport rate (ETR) is expressed in $\mu \mathrm{mol} \mathrm{e}^{-} \mathrm{m}^{-2} \mathrm{~s}^{-1}$. An uncertainty lies with these units as 
area. Therefore we would like to follow up on an idea that was proposed previously (Joliot and Joliot, 2002): ECS can be calibrated on an internal standard to determine the number of electrons transferred per photosystem per unit time $\left(\mathrm{e}^{-} \mathrm{PS}^{-1} \mathrm{~s}^{-1}\right)$. Here the unit area is the functional unit of photosynthesis, the photosystems themselves.

\section{Materials and Methods}

Chlorella sorokiniana WT, and chloroplast ATPase-deficient mutant SL8 (Rappaport et al., 1999) were heterotrophically grown at $20^{\circ} \mathrm{C}$, in continuous light $\left(20 \mu \mathrm{mol}_{\text {photons }} \mathrm{m}^{-2} \mathrm{~s}^{-1}\right)$, in Tris-acetate-phosphate medium. Prior to each experiment, cells were concentrated and resuspended in $10 \%$ Ficoll to a concentration of $\sim 15 \mu \mathrm{g}_{\mathrm{Chl}} \mathrm{mL}^{-1}$, then adapted for $>15 \mathrm{~min}$ in Erlenmeyer flasks stirred at $150 \mathrm{rpm}$ prior to measurements. 3-(3,4-dichlorophenyl)-1,1dimethyl-urea (DCMU) was used at a final concentration of $10 \mu \mathrm{M}$, hydroxylamine at 10 $\mathrm{mM}$.

Absorption spectroscopy - The ElectroChromic Shift (ECS) of carotenoids was measured as an absorbance changes $(\Delta \mathrm{A})$ with a Joliot-type spectrophotometer using a Xenon flashlamp fitted to a Jobin-Yvon HL300 f/2 monochromator (Joliot et al., 1980) or to a white LED fitted to a $520 \mathrm{~nm}$ band pass dielectric filter (JTS-10, Biologic). Similar measurements can be done with Walz Dual-Pam 100 or MultispeQ. The detecting photodiodes were protected by a combination of BG39 (Schott) and CVI low-pass dielectric filters (600 nm). Action spectra were obtained with continuous light provided with a SPEX illuminator as excitation light (a Xenon arc lamp fitted to a Jobin Yvon 1681 Minimate f/4 monochromator) and computercontrolled shutter (Uniblitz).

The JTS-10 is supplied with a detection filter centered at $546 \mathrm{~nm}$ that can be used for deconvolution of cytochrome $f(554 \mathrm{~nm})$ or $b(563 \mathrm{~nm})$ signals. We find that, while it is necessary to correct for cytochrome kinetics, it was not for ECS in the present study where illuminations were rather short $(<10 \mathrm{~s})$. For longer illuminations, inducing de-epoxidation of violaxanthin to zeaxanthin (Ilioaia et al., 2011), thylakoid membrane swelling and scattering changes or chloroplast migration in plant leaves, it would become necessary to extract pure ECS traces by subtracting $546 \mathrm{~nm}$ from $520 \mathrm{~nm}$ absorbance changes. For such applications, the technique of "continuous ECS-indicated recording" via the dual-wavelength (550-520 $\mathrm{nm}$ ) accessory of the Dual-PAM-100 may be more appropriate (Klughammer et al., 2013). 
103 Saturating flash - If a "single turnover saturating flash" is applied to the photosynthetic 104 material, the ECS signal $\left(\Delta \mathrm{A}_{520} \mathrm{~nm}\right)$ is proportional to the amount of active (or open) 105 photosystems, $\mathrm{PS}_{\mathrm{o}}$. The technical requirements are the following: the flash must be short 106 (typically $\leq 1 \mu \mathrm{s}$, otherwise PSI can undergo a second turnover during the flash), and intense 107 (typically $\geq 1 \mathrm{~mJ}$, saturation is reached when twice as many photons have no significant effect $108(<10 \%)$ to increase the signal). Pulsed lasers (flash-lamp pumped and frequency-doubled $109 \mathrm{Nd}$ :YAG lasers with dyes, $\leq 10 \mathrm{~ns}$ and $\geq 30 \mathrm{~mJ}$ ) typically meet these criteria. Here flashes at $110700 \mathrm{~nm}$ were delivered by an OPO pumped at $532 \mathrm{~nm}$ by a frequency-doubled Nd:YAG laser 111 (Surelite II, Continuum). A saturating single-turnover flash gives the amount of "open" or 112 "potentially active" photosystems: i.e. centers in the PA state if we call P the reduced form of 113 the Primary donor and A the oxidized form of the Acceptor. The flash will close the centers, 114 forming the $\mathrm{P}^{+} \mathrm{A}^{-}$state. In the dark, all centers are in the PA state, and during a continuous 115 illumination some centers can be under the $\mathrm{P}^{+} \mathrm{A}$ or $\mathrm{PA}^{-}$states, which are other forms of closed 116 centers. $\mathrm{PS}_{\mathrm{o}}$ being the relative amplitude of the signal created by the flash is therefore the 117 fraction of PA.

Data treatment - ECS kinetics were fitted by R-scripts. ECS rise and decay were respectively

120 fitted to a linear model (initial flow rate $I$ ) and first order exponential decay (pseudo steady121 state flow rate $J$ ), using the $n l s$ (Non-Linear Squares) function for the latter.

\section{Results}

124 Figure 1A shows the spectrum of light-induced absorbance changes $(\Delta \mathrm{A}) 20 \mu \mathrm{s}$ after a 125 saturating flash inducing an increase in trans-thylakoid $\Delta \psi$. Similarly as in (Witt, 1979), the 126 spectrum shows a peak at $518 \mathrm{~nm}$ corresponding to carotenoid absorption shifting to longer 127 wavelengths. After the flash, $\Delta \mathrm{A}$ decays to zero in about $100 \mathrm{~ms}$, see Figure $1 \mathrm{~B}$ (a). In the 128 absence of ATPase, the ECS decay is much slower and the "slow electrogenic phase" of 129 electron transfer in the low-potential chain ( $b$-type hemes) of cytochrome $b_{6} f$ complex is 130 observed, see Figure 2A. Subsequent flashes increase $\Delta \mathrm{A}_{520 \mathrm{~nm}}$ by the same amount, showing 131 ECS is proportional to $\Delta \psi$. The amplitude of the flash-induced signal $\Delta \mathrm{A}_{20 \mu \text { s }}$ is used as a 132 simple calibration of 1 charge separated per photosystem (PS) and used for normalization of $133 \Delta$ A. Hereafter electron transfer rates $\left(\right.$ in s$^{-1}$ ) are converted into electron flow rates (in $\mathrm{e}^{-} \mathrm{PS}^{-}$ $\left.134{ }^{1} \mathrm{~s}^{-1}\right)$. 
136 Initial phase of ECS - A continuous illumination induces multiphasic changes in $\Delta \mathrm{A}_{520 \mathrm{~nm}}$ 137 (Figure 1B). At the onset of illumination, the photosynthetic membrane is charged as a 138 capacitor, the conversion of photons into electrons transferred across the membrane builds-up $139 \Delta \psi$. Figure 1B (left) shows that ECS increases rather linearly in the first tens of milliseconds. 140 In the absence of ATPase (Figure 2B), $\Delta \mathrm{A}_{520 \mathrm{~nm}}$ follows a straight slope over a much larger 141 time range. Therefore, in order to estimate in the WT the initial photochemical flow rate $I$ we need to fit the slope of the ECS rise on the first three datapoints $(\mathrm{t} \leq 10 \mathrm{~ms})$. $I$ is proportional to the light intensity (Figure 2C). Inhibition of PSII has contrasting effects on the initial 144 phase: when PSII is blocked only on the acceptor side, the initial flow rate is identical to the 145 non-treated conditions (DCMU blocks the $\mathrm{Q}_{\mathrm{A}}$ to $\mathrm{Q}_{\mathrm{B}}$ electron transfer, but trans-membrane 146 charge separation $\mathrm{P}_{680}{ }^{+} \mathrm{Q}_{\mathrm{A}}^{-}$still occurs); while when PSII is blocked at both donor and acceptor side (DCMU and hydroxylamine), the ECS rise is about twice slower (only PSI contributes to $\Delta \psi)$. This method can be used to assess the relative antenna size and the relative amounts of photosystems I and II. It also provides a way to calibrate the actinic effect of different light sources (of different wavelengths or bandwidths), converting incident photons $\mu \mathrm{mol}_{\text {photons }} \mathrm{m}^{-2} \mathrm{~s}^{-1}$ into effective photons $\mathrm{e}^{-} \mathrm{PS}^{-1} \mathrm{~s}^{-1}$.

Pseudo steady-state and decay phase - After all photosystems were hit by photons (amplitude $\Delta \mathrm{A} \sim 1$, at $t \sim 20 \mathrm{~ms}$ in Figure 1B, see inset on the left), the increase of ECS slows down, and a typical shoulder-peak-and-slow-descent is observed. The shape and amplitude of this curve is dependent upon the light intensity, the redox state (aerobic/anaerobic) or the nature of the sample (plant leaf or algal suspension), it is mostly influenced by the activation status of the chloroplast ATPase, the inter-conversion between $\Delta \psi$ and $\Delta \mathrm{pH}$, and possibly the activation of cyclic electron flow. At $t \geq 3 \mathrm{~s}$ after the onset of illumination, ECS is in its "slow descent" phase, i.e. it does not vary much over time and it can be defined as a pseudo steady-state. When illumination stops, a sharp decay of ECS is observed (see Figure 1B right). It reflects the discharge of the membrane (efflux) that corresponded to the charge flow rate in the light, we denote $J$ this flow at pseudo steady-state.

A transmission coefficient for electrons - In one quick measurement, ECS can therefore monitor the initial $(I)$ and pseudo steady-state $(J)$ rate of photosynthesis. To our knowledge, the only other way to get to these parameters is using fast-response bare $\mathrm{O}_{2}$ electrode with 
168 modulated illumination (Haxo and Blinks, 1950; Joliot, 1965; Myers and French, 1960).

169 Figure 3A shows that $I$ increases linearly with irradiance. This is because when the 170 photosystems are open, they are not limiting for electron transfer. In contrast $J$, here fitted to a 171 Michaelis-Menten equation (solid line), reaches a plateau at $V_{\max }=88 \mathrm{e}^{-} \mathrm{s}^{-1} \mathrm{PS}^{-1}$. It shows 172 that photosynthesis saturates at high light intensities and suggests that photosystems are 173 getting inactive during continuous illumination. The closure of photosystems can be assessed 174 directly by adding a single turnover saturating flash in the slow descent at $t=3 \mathrm{~s}$ (see 175 Figure 1B). The flash gives a step increase with an amplitude equal to the fraction of open 176 centers $0 \leq \mathrm{PS}_{0} \leq 1 . J$ is always smaller than $I$, and the ratio $0 \leq J / I \leq 1$ is the yield of 177 electron transfer. In other words $J / I$ is the probability for an electron, initially transferred in a 178 photosystem, to be steadily transported through the chain. This dimensionless parameter is a 179 transmission coefficient.

The slippery transmission of photosynthesis - A photosynthetic apparatus with perfect transmission would give $J / I$ equal to $\mathrm{PS}_{\mathrm{o}}$. In other words, for a first order rate reaction, the steady-state flow would be equal to the maximal rate (all centers open) in proportion to the fraction of centers remaining open at steady-state. In Figure $3 \mathrm{~B}$ where $J / I$ is plotted against $\mathrm{PS}_{\mathrm{o}}$, data points do not align diagonally: the transmission coefficient is always smaller than the relative amount of open photosystems. It suggests that photosynthetic electron transfer is affected by the diffusion of the electron carriers. It is possible that a reduced PSII acceptor does not find its way towards an oxidized PSI donor before charge recombination occurs with a rate $k_{\text {rec. }}$

190 This problem of diffusion in the photosynthetic chain can be treated with a very economical model with only one parameter $k_{\text {rec }}$, a rate of charge recombination (Lavergne, 2009). We found that $k_{\text {rec }}$ values comprised between 200 and $700 \mathrm{~s}^{-1}$ accounted for the gap between the measured transmission coefficient $J / I$ and the fraction of centers remaining open in the light

$194 \mathrm{PS}_{\mathrm{o}}$. The solid and dotted lines correspond to an intermediary value $k_{\mathrm{rec}}=350 \mathrm{~s}^{-1}$. A rate of $350 \mathrm{~s}^{-1}\left(t_{1 / 2}=2 \mathrm{~ms}\right)$ is in the range of charge recombination in PSII or PSI. At very low light intensities, when $\mathrm{PS}_{\mathrm{o}}$ approaches 1 in Figure $3 \mathrm{~B}$, the vertical error bars become rather large, this is because of the division by $I$ whose values tend to zero. Within experimental accuracy, the solid lines fit experimental data more satisfactorily than the dotted lines in Figure 3B, and also in Figure 3A where $J$ rises more slowly than $I$ (see Figure 3A inset). It shows that the maximum transmission coefficient, $\mathrm{V}_{\max } / \mathrm{K}_{\mathrm{m}}$ is reached when irradiance tends to zero, here 
202 machinery has $>17 \%$ energy losses, even at idle speed. If one considers Photosystem I and

203 Photosystem II as transmission shafts, the coupling in the photosynthetic chain compares to a

204 friction belt, rubbing on the pulleys and dissipating mechanical energy as heat. This energy 205 dissipation is accounted for in the $k_{\text {rec }}$ parameter: frictions may encompass unpaired PSI-PSII 206 antenna sizes (state transitions), non-photochemical quenching, non- $\mathrm{Q}_{\mathrm{B}}$-reducing centers, as 207 well as stochastic motion of electron carriers.

209 Increasing the frictions - In the experiments shown in Figure 4, the wavelength of the actinic 210 light was varied from 650 to $710 \mathrm{~nm}$, in order to change the excitation balance between PSI 211 and PSII. Yet, stronger light intensities were used at less absorbed wavelengths so that the 212 actinic effect of the light was the same (same $F_{\mathrm{i}}$, see Figure 4B). Figure 4A shows the ECS 213 signal is much different under $680 \mathrm{~nm}$ excitation than at $710 \mathrm{~nm}$. When both photosystems are 214 excited, $\Delta \psi$ builds up to a much higher level. This is not because of a slower decay of $\Delta \psi$ 215 because in this instance $\Delta \psi$ decays much faster, $30 \mathrm{e}^{-} \mathrm{s}^{-1} \mathrm{PS}^{-1}$, than when only PSI is excited, $2168 \mathrm{e}^{-} \mathrm{s}^{-1} \mathrm{PS}^{-1}$ (Figure 4C). A "red drop" of the transmission coefficient $J / I$ corresponds to the 217 drop of the maximum quantum yield for $\mathrm{O}_{2}$ evolution (Emerson and Lewis, 1943). It is 218 expected since these two parameters are homogenous: they both refer to a yield. Nevertheless, $219 \mathrm{O}_{2}$ evolution drops more steeply than the transmission coefficient. It shows that far-red 220 photons, absorbed by PSI and not by PSII, do not evolve $\mathrm{O}_{2}$ but sustain cyclic electron flow 221 around PSI, although at a much slower rate than linear electron flow, as previously reported 222 for DCMU treated samples (Alric, 2014, 2010; Maxwell and Biggins, 1976). Under such 223 conditions $\mathrm{P}_{700}{ }^{+}$accumulates and PSI is closed while PSII centers stay potentially active and 224 contribute to $\mathrm{PS}_{\mathrm{o}}$. When PSI and PSII excitation is unbalanced, the transmission coefficient in 225 the chain decreases. In the long wave-range of photosynthesis, spinning Photosystem I transmission shaft while Photosystem II keeps still increases the frictions in the chain.

\section{Conclusion}

229 Half-saturation of photosynthesis was observed for a time delay of $0.02 \mathrm{~s}$ between short 230 saturating flashes (Emerson and Arnold, 1932). In modern terms, it corresponds to an electron 231 flow of $1 / 0.02=50 \mathrm{e}^{-} \mathrm{s}^{-1} \mathrm{PS}^{-1}$. In the present work, ECS measurements give a very similar 232 value for half-saturation of photosynthesis: $V_{\max } / 2=44 \mathrm{e}^{-} \mathrm{s}^{-1} \mathrm{PS}^{-1}$ (see Figure 3A).

233 Calibration of photosynthesis measurements on single turnover saturating flashes is therefore 234 a way to compare results from lab to lab and from instrument to instrument. It also offers to 235 precisely quantify the yield of photosynthesis. These "standard units" are independent from 
the chlorophyll content (sample concentration, or thickness of the leaf) and are therefore also "portable" between photosynthetic organisms.

\section{Acknowledgements}

240 This work was supported by CEA, CNRS and grant from Region Sud APR-EX 2019-03086 and 2016-03216.

\section{Author contribution}

244 C.M. performed experiments and analyzed data, J.A. designed research, analyzed data and wrote the manuscript.

\section{Data Availability Statement}

All data supporting the findings of this study are available within the paper.

\section{References}

Alric, J., 2014. Redox and ATP control of photosynthetic cyclic electron flow in Chlamydomonas reinhardtii: (II) Involvement of the PGR5-PGRL1 pathway under anaerobic conditions. Biochimica et Biophysica Acta (BBA) - Bioenergetics 1837, 825-834. https://doi.org/10.1016/j.bbabio.2014.01.024 Alric, J., 2010. Cyclic electron flow around photosystem I in unicellular green algae. Photosynth Res 106, 47-56. https://doi.org/10.1007/s11120-010-9566-4

Avenson, T.J., Cruz, J.A., Kanazawa, A., Kramer, D.M., 2005. Regulating the proton budget of higher plant photosynthesis. PNAS 102, 9709-9713. https://doi.org/10.1073/pnas.0503952102 Avenson, T.J., Cruz, J.A., Kramer, D.M., 2004. Modulation of energy-dependent quenching of excitons in antennae of higher plants. Proc Natl Acad Sci U S A 101, 5530-5535. https://doi.org/10.1073/pnas.0401269101 Cruz, J.A., Sacksteder, C.A., Kanazawa, A., Kramer, D.M., 2001. Contribution of electric field (Delta psi) to steady-state transthylakoid proton motive force (pmf) in vitro and in vivo. control of pmf parsing into Delta psi and Delta $\mathrm{pH}$ by ionic strength. Biochemistry 40, 12261237. https://doi.org/10.1021/bi0018741

Duysens, L.N., 1954. Reversible Changes in the Absorption Spectrum of Chlorella upon Irradiation. Science 120, 353-354. https://doi.org/10.1126/science.120.3113.353 Emerson, R., Arnold, W., 1932. THE PHOTOCHEMICAL REACTION IN PHOTOSYNTHESIS. Journal of General Physiology 16, 191-205. https://doi.org/10.1085/jgp.16.2.191 Emerson, R., Lewis, C.M., 1943. The Dependence of the Quantum Yield of Chlorella Photosynthesis on Wave Length of Light. American Journal of Botany 30, 165-178. https://doi.org/10.1002/j.1537-2197.1943.tb14744.x Haxo, F.T., Blinks, L.R., 1950. PHOTOSYNTHETIC ACTION SPECTRA OF MARINE ALGAE. Journal of General Physiology 33, 389-422. https://doi.org/10.1085/jgp.33.4.389 Ilioaia, C., Johnson, M.P., Duffy, C.D.P., Pascal, A.A., van Grondelle, R., Robert, B., Ruban, A.V., 2011. Origin of Absorption Changes Associated with Photoprotective Energy 
Dissipation in the Absence of Zeaxanthin*. Journal of Biological Chemistry 286, 91-98. https://doi.org/10.1074/jbc.M110.184887 Joliot, P., 1965. Cinétiques des réactions liées a l'émission d'oxygène photosynthétique. Biochimica et Biophysica Acta (BBA) - Biophysics including Photosynthesis 102, 116-134. https://doi.org/10.1016/0926-6585(65)90207-4

Joliot, P., Béal, D., Frilley, B., 1980. Une nouvelle méthode spectrophotométrique destinée à l'étude des réactions photosynthétiques. J. Chim. Phys. 209-216.

Joliot, P., Delosme, R., 1974. Flash-induced $519 \mathrm{~nm}$ absorption change in green algae. Biochimica et Biophysica Acta (BBA) - Bioenergetics 357, 267-284. https://doi.org/10.1016/0005-2728(74)90066-8

Joliot, P., Joliot, A., 2002. Cyclic electron transfer in plant leaf. PNAS 99, 10209-10214. https://doi.org/10.1073/pnas.102306999

Junge, W., 1970. The Critical Electric Potential Difference for Photophosphorylation. European Journal of Biochemistry 14, 582-592. https://doi.org/10.1111/j.14321033.1970.tb00327.x

Kanazawa, A., Kramer, D.M., 2002. In vivo modulation of nonphotochemical exciton quenching (NPQ) by regulation of the chloroplast ATP synthase. PNAS 99, 12789-12794. https://doi.org/10.1073/pnas. 182427499

Klughammer, C., Siebke, K., Schreiber, U., 2013. Continuous ECS-indicated recording of the proton-motive charge flux in leaves. Photosynth Res 117, 471-487.

https://doi.org/10.1007/s11120-013-9884-4

Kunz, H.-H., Gierth, M., Herdean, A., Satoh-Cruz, M., Kramer, D.M., Spetea, C., Schroeder, J.I., 2014. Plastidial transporters KEA1, -2, and -3 are essential for chloroplast osmoregulation, integrity, and $\mathrm{pH}$ regulation in Arabidopsis. PNAS 111, 7480-7485. https://doi.org/10.1073/pnas.1323899111

Lavergne, J., 2009. Clustering of Electron Transfer Components: Kinetic and Thermodynamic Consequences, in: Laisk, A., Nedbal, L., Govindjee (Eds.), Photosynthesis in Silico: Understanding Complexity from Molecules to Ecosystems, Advances in Photosynthesis and Respiration. Springer Netherlands, Dordrecht, pp. 177-205. https://doi.org/10.1007/978-14020-9237-4 8

Maxwell, P.C., Biggins, J., 1976. Role of cyclic electron transport in photosynthesis as measured by the photoinduced turnover of P700 in vivo. Biochemistry 15, 3975-3981. https://doi.org/10.1021/bi00663a011

Myers, J., French, C.S., 1960. Evidences from Action Spectra for a Specific Participation of Chlorophyll b in Photosynthesis. Journal of General Physiology 43, 723-736. https://doi.org/10.1085/jgp.43.4.723 Rappaport, F., Finazzi, G., Pierre, Y., Bennoun, P., 1999. A new electrochemical gradient generator in thylakoid membranes of green algae. Biochemistry 38, 2040-2047. https://doi.org/10.1021/bi982351k Sacksteder, C.A., Kramer, D.M., 2000. Dark-interval relaxation kinetics (DIRK) of absorbance changes as a quantitative probe of steady-state electron transfer. Photosynthesis Research 66, 145. https://doi.org/10.1023/A:1010785912271

Witt, H.T., 1979. Energy conversion in the functional membrane of photosynthesis. Analysis by light pulse and electric pulse methods: The central role of the electric field. Biochimica et Biophysica Acta (BBA) - Reviews on Bioenergetics 505, 355-427. https://doi.org/10.1016/0304-4173(79)90008-9 
Figure 1. ECS spectrum and kinetics in Chlorella sorokiniana intact cells, here measured with a Joliot-type spectrophotometer.

(A) Spectrum of absorbance changes $(\Delta \mathrm{A})$, peaking at $518 \mathrm{~nm}$, detected $20 \mu$ s after a single turnover saturating flash.

(B) Typical kinetics of ECS, induced by a $\sim 5 \mathrm{~s}$ continuous red illumination (140 $\mu \mathrm{mol}_{\text {photons }} \mathrm{m}^{-2} \mathrm{~s}^{-1}, 638 \mathrm{~nm}$, white bar). The signal was normalized on the amplitude of the single turnover flash (upward arrow) in the dark (a). Insets show the fast phases of rise and decay in $\Delta \psi$ at the onset (b) and offset (d) of light. $I$ is the initial electron flow rate; $J$ is the steady-state flow rate. The relative amount of photosystems remaining open during the light, $\mathrm{PS}_{\mathrm{o}}$, is probed with a saturating flash (c).

Figure 2. Inactivating ATPase extends the range where $\Delta \mathrm{A}_{520 \mathrm{~nm}}$ increases with absorbed photons (SL8 mutant line).

(A) ECS following a train of 4 flashes (upward arrows). The ECS signal induced by the first flashes is of equal amplitude (see vertical bar: $\Delta \psi$ amplitude generated by the transfer of one electron per photosystem). The decay of the signal is very slow (low membrane conductivity).

(B) ECS increases linearly with light duration. The linear range is larger in the ATPase-less strain (solid lines) than in WT (dotted lines). The initial rates, calculated between 0 and $10 \mathrm{~ms}$ are identical.

(C) The initial rate of ECS increases linearly with light intensity. $10 \mu \mathrm{M}$ DCMU does not block charge separation in PSII, but DCMU and hydroxylamine (10 $\mathrm{mM})$ do, and decrease the initial rate.

(A) Initial $(I)$ and steady-state $(J)$ electron fluxes plotted against light intensity. $I$ is fitted to a straight-line, $J$ to a Michaelis-Menten model, with $\mathrm{V}_{\max }=88 \mathrm{e}^{-} \mathrm{PS}^{-1} \mathrm{~s}^{-1}$ and $\mathrm{K}_{\mathrm{M}}=106 \mathrm{e}^{-} \mathrm{PS}^{-}$ ${ }^{1} \mathrm{~s}^{-1}$ (solid line). The inset shows an expanded view at low-light conditions. The dashed line is when forcing $K_{M}=V_{\max }$ in the fit.

(B) Plot of the transmission coefficient $J / I$ against the fraction of open photosystems $\mathrm{PS}_{\mathrm{o}}$. The solid line corresponds to a diffusive model with intrinsic losses, considering charge recombination at a rate $k_{\mathrm{rec}}=350 \mathrm{~s}^{-1}$. The dashed line simulates the same diffusive model with maximum efficiency at low light $\left(\mathrm{K}_{\mathrm{M}}=\mathrm{V}_{\max }\right.$, i.e. same initial slope for $I$ and $J$, see (D) inset). The dotted diagonal corresponds to an "ideal" photosynthetic apparatus with perfect transmission (for $k_{\mathrm{rec}}=0$ ).

367 In (A), (B) and Figure 1B, open symbols represent the same dataset (obtained at 140 $\left.368 \mu \mathrm{mol}_{\text {photons }} \mathrm{m}^{-2} \mathrm{~s}^{-1}\right)$. 


\section{$370 \quad$ Figure 4. ECS action spectra}

371 (A) ECS kinetics induced by $680 \mathrm{~nm}$ and $710 \mathrm{~nm}$ continuous light excitation.

372 (B) Light intensity (stronger at $710 \mathrm{~nm}$ than $680 \mathrm{~nm}$ ) was adjusted to give the same initial 373 rise.

374 (C) Steady-state electron flow is much slower under $710 \mathrm{~nm}$ light excitation specific to PSI.

375 (D) Photosynthesis action spectra: red drop in $\mathrm{O}_{2}$ quantum yield (reproduced from (Emerson 376 et al., 1957)) and transmission coefficient calculated from ECS $(J / I)$. Under $710 \mathrm{~nm}$ 377 illumination $\mathrm{P}_{700}{ }^{+}$is accumulated and PSI centers are closed. 